\title{
Organic micropollutants in the Yangtze River: Seasonal occurrence and annual loads
}

\author{
Weixiao Qi ${ }^{\text {a }}$, Beat Müller ${ }^{\text {b,* }}$, Benoit Pernet-Coudrier ${ }^{c}$, Heinz Singer $^{c}$, Huijuan Liu $^{\text {a,** }}{ }^{\text {, }}$ \\ Jiuhui $\mathrm{Qu}^{\mathrm{a}}$, Michael Berg ${ }^{\mathrm{c}}$ \\ a State Key Laboratory of Environmental Aquatic Chemistry, Research Center for Eco- Environmental Sciences, Chinese Academy of Sciences, Beijing 100085, China \\ ${ }^{\mathrm{b}}$ Eawag, Swiss Federal Institute of Aquatic Science and Technology, 6047 Kastanienbaum, Switzerland \\ c Eawag, Swiss Federal Institute of Aquatic Science and Technology, 8600 Dübendorf, Switzerland
}

\section{H I G H L I G H T S}

- The Yangtze River drains $40 \%$ of China's mainland with 400 million inhabitants

- Monthly concentrations and annual loads of organic pollutants were determined

- Seasonality of loads of PAHs, most pesticides, and antiinfectives were concise

- In spite of low concentrations due to high water discharge, pollutant loads are considerable

\section{A R T I C L E I N F O}

\section{Article history:}

Received 13 August 2013

Received in revised form 3 November 2013

Accepted 3 November 2013

Available online 10 December 2013

\section{Keywords:}

Yangtze River

Organic micropollutants

Pharmaceuticals

Pesticides

Household chemicals

Polycyclic aromatic hydrocarbons

\begin{abstract}
A B S T R A C T
Twenty percent of the water run-off from China's land surface drains into the Yangtze River and carries the sewage of approximately 400 million people out to sea. The lower stretch of the Yangtze therefore offers the opportunity to assess the pollutant discharge of a huge population. To establish a comprehensive assessment of micropollutants, river water samples were collected monthly from May 2009 to June 2010 along a crosssection at the lowermost hydrological station of the Yangtze River not influenced by the tide (Datong Station, Anhui province). Following a prescreening of 268 target compounds, we examined the occurrence, seasonal variation, and annual loads of 117 organic micropollutants, including 51 pesticides, 43 pharmaceuticals, 7 household and industrial chemicals, and 16 polycyclic aromatic hydrocarbons (PAHs). During the 14-month study, the maximum concentrations of particulate PAHs (1-5 $\mu \mathrm{g} / \mathrm{g}$ ), pesticides (11-284 ng/L), pharmaceuticals (5-224 ng/L), and household and industrial chemicals (4-430 $\mathrm{ng} / \mathrm{L}$ ) were generally lower than in other Chinese rivers due to the dilution caused of the Yangtze River's average water discharge of approximately $30,000 \mathrm{~m}^{3} / \mathrm{s}$. The loads of most pesticides, anti-infectives, and PAHs were higher in the wet season compared to the dry season, which was attributed to the increased agricultural application of chemicals in the summer, an elevated water discharge through the sewer systems and wastewater treatment plants (WWTP) as a result of high hydraulic loads and the related lower treatment efficiency, and seasonally increased deposition from the atmosphere and runoff from the catchment. The estimated annual load of PAHs in the river accounted for some $4 \%$ of the total emission of PAHs in the whole Yangtze Basin. Furthermore, by using sucralose as a tracer for domestic wastewater, we estimate a daily disposal of approximately 47 million $\mathrm{m}^{3}$ of sewage into the river, corresponding to $1.8 \%$ of its average hydraulic load. In summary, the annual amounts flushed by the Yangtze River into the East China Sea were $2.9 \times 10^{6}$ tons of dissolved and particulate organic carbon (DOC and POC), 369 tons of PAHs, 98 tons of pesticides, 152 tons of pharmaceuticals, and 273 tons of household and industrial chemicals. While the concentrations seem comparably moderate, the pollutant loads are considerable and pose an increasing burden to the health of the marine coastal ecosystem.
\end{abstract}

(c) 2013 Elsevier B.V. All rights reserved.

\footnotetext{
* Corresponding author. Tel.: +4158765 2149

** Corresponding author. Tel.: + 861062849128.

E-mail addresses: beat.mueller@eawag.ch (B. Müller), hjliu@rcees.ac.cn (H. Liu).
}

\section{Introduction}

The Yangtze is the largest river in Asia and the third largest river in the world in terms of length $(6,300 \mathrm{~km})$ and discharge $\left(900 \mathrm{~km}^{3} / \mathrm{yr}\right)$. It flows through several megacities of China, such as Chongqing, Wuhan, Nanjing, Wuxi, Suzhou, and Shanghai. The rapid economic 
growth and expansion of these cities have placed enormous environmental pressure on the Yangtze River, including overexploitation in terms of hydropower (Qiu, 2012), fishing, cargo ship traffic, the disposal of sewage and industrial waste (Dudgeon, 2010), and an inundation of polluted land (Zhang and Lou, 2011; Yang et al., 2012). At the same time, a rapidly increasing urban population depends on the Yangtze River as the sole source of drinking water, although the concentrations of many organic pollutants, such as polycyclic aromatic hydrocarbons (PAHs), polychlorinated biphenyls (PCBs), phthalates, pesticides, pharmaceuticals, and many other household, agricultural, and industrial chemicals, are increasing and threaten water security (He et al., 2011; Müller et al., 2008, 2012). Moreover, the cocktail of inorganic nitrogen, phosphorus, oil hydrocarbons, organic matter, and heavy metals is expected to fuel algae blooms and "red tides" (Li and Dag, 2004), and trace elements and persistent organic chemicals-especially those related to suspended particles-may accumulate in the food chain of this productive shelf region, thus increasing the threat to human health.

In the last decade, many studies have focused on the contamination of sediment in the Yangtze estuary by organic micropollutants including PAHs (Liu et al., 2000; Xu et al., 2001; Hui et al., 2009), aliphatic hydrocarbons (Bouloubassi et al., 2001), organochlorine pesticides (OCPs) (Liu et al., 2003, 2008), PCBs (Liu et al., 2003; Shen et al., 2006), and polybrominated diphenyl ethers (Chen et al., 2006; Shen et al., 2006).

Only a few studies have been conducted using sediment along the course of the Yangtze, as it is difficult to find representative locations that provide continuous sedimentation without erosion during flooding. The large shallow lakes are especially suitable for this purpose, and Z.F. Yang et al. (2011) showed that the deposition rates of PAHs of up to $3.9 \mathrm{mg} \mathrm{m}^{-2} \mathrm{yr}^{-1}$ in the sediment of Donghu Lake near Wuhan trace the economic development and are the highest in China. Except for the lakes, the Yangtze River sections at Wuhan and Nanjing are the main research areas. Xu et al. (2000) investigated the persistent pollutants, including polychlorinated organic compounds (PCOCs) and PAHs, in sediment from the Nanjing section of the Yangtze and reported up to $10 \mathrm{ng} / \mathrm{g}$ of PCOCs and between $16 \mathrm{ng} / \mathrm{g}$ to $765 \mathrm{ng} / \mathrm{g}$ of PAHs. Surface sediment from the Yangtze and several tributaries in the vicinity of Wuhan were analyzed for PAHs by C.L. Feng et al. (2007), for pentachlorophenol (PCP) by Tang et al. (2007), for phthalic acid esters (PAEs) by Wang et al. (2008), and for PCBs by Yang et al. (2009). Compared to concentrations detected in other large rivers of the world, the concentrations of PCP and PCBs were relatively low, the concentration of PAEs was similar, and the concentration of PAHs was higher.

Analyzing sediment is an excellent tool to document the temporal development of pollution concentrations, but it requires undisturbed and uniform deposition. Yet, combining the analysis of water samples and suspended particulate matter with water discharge data, allows the quantification of current concentrations and loads. Frequent measurements permit one to establish the seasonality, ways of transport, and possible decomposition in the environment, as well as to trace sources. Relatively few studies using this method have been performed in the Yangtze River so far, and they have mostly focused on distinct classes of compounds. The Three Gorges Reservoir is currently receiving attention; several articles reviewing research on POPs in the reservoir have been published recently (Wolf et al., 2013; Wang et al., 2012).

In the vicinity of Nanjing (Jiangsu province), PCOCs were sampled at four locations in May 1998 by Jiang et al. (2000), who determined concentrations in the lower ng/L range. Sun et al. (2002) detected 18 PCOCs in monthly water samples from December 1998 to October 1999 upstream of Nanjing City in concentrations less than $3 \mathrm{ng} / \mathrm{L}$. Unfortunately, the loads were not quantified, but the concentration ranges of PCOCs that were determined 10 years earlier by Bao and Zhang (1990) were approximately 50 times higher, which might be due to the prohibition of the use of these chemicals 20 years ago. Pentachlorophenol residues were detected by Tang et al. (2007) in samples of suspended particles at Wuhan even though the production and application of this class of chemicals are banned in China. Phthalates at Wuhan exceed the water quality criteria of China (Wang et al., 2008), and the high concentrations of PAHs in the Wuhan section of the Yangtze have been mainly attributed to the burning of coal and wood (C.L. Feng et al., 2007). Semi-volatile compounds in the river water at Nanjing were studied in January 2007 by Wu et al. (2009), who allocated $44 \%$ to $65 \%$ of the input to industrial and domestic sewage. He et al. (2011) analyzed samples for persistent toxic substances (such as OCPs, PAHs, PCBs, and phthalates) collected from five sections of the Yangtze River around Nanjing and compared the concentrations with other rivers in China and other countries. Generally, concentrations of organic micropollutants were low in comparison with other rivers due to the large dilution by the enormous amount of water in the Yangtze.

While the concentration of a chemical in river water may be relevant for the toxicity and accumulation in the food chain, only the quantification of loads allow for comparisons of the pollution at different times and different locations, as well as emission rates and the quantification of sources and sinks. In spite of the past high-quality analytical investigations, there is an obvious lack of long-term monitoring data of organic pollutants and their distribution between water and suspended particulate matter, which would allow for the characterization of seasonality and the estimation of annual loads.

In November 2006, Müller et al. (2008) studied the middle and lower part of the Yangtze River from the Three Gorges Dam downstream to Shanghai and presented a snapshot overview of the longitudinal distribution of water constituents and anthropogenic chemicals. These authors screened for organic pollutants with limits of detection of 0.1 to $0.5 \mu \mathrm{g} / \mathrm{L}$ for dissolved compounds and 0.1 to $5 \mu \mathrm{g} / \mathrm{g}$ for particleassociated compounds, thereby detecting only the most notorious pollutants due to the high water discharge of the Yangtze. In a follow-up paper, Müller et al. (2012) characterized seasonality, the anthropogenic contribution to inorganic compounds and long-term temporal trends, and estimated annual loads using monthly measurements at Datong from May 2009 to June 2010.

The present study investigated the abundance, seasonality, and annual loads of organic micropollutants during a full hydrological year at Datong (Anhui province), the location of the lowermost hydrological station of the Yangtze River not influenced by the sea. We screened our water samples for 268 household chemicals, pharmaceuticals, pesticides, biocides, industrial chemicals, and associated metabolites. We also quantified bulk dissolved organic carbon (DOC) and particulate organic carbon (POC). The comprehensive dataset allowed us to accomplish the following objectives:

- Make accurate estimations of annual loads and discuss the seasonality. Persistent household chemicals allowed us to estimate the size of the population disposing their wastewater into the river. We were able to estimate the proportion of untreated wastewater in the Yangtze using selectively degradable compounds.

- Reflect on activities related to the use of chemicals in one of the world's largest catchments, which is home to one-third of China's population and is an integration point of the environmental impacts of this fast-growing economy.

- Provide a database and a reference point for future assessments of changes in water quality.

\section{Materials and methods}

\subsection{Sampling}

Water samples from the Yangtze River were collected monthly from May 2009 to June 2010 about $12 \mathrm{~km}$ upstream of the Station of Datong, approximately $600 \mathrm{~km}$ from the East China Sea (see Fig. 1). At this location, the Yangtze drains a catchment area of 1.7 million $\mathrm{km}^{2}$ (Zhang et al., 2006). Three samples were collected from a ship in the crosssection of the river (geopositions Y1: N $30^{\circ} 4653$, E $117^{\circ} 3733$; Y2: N 


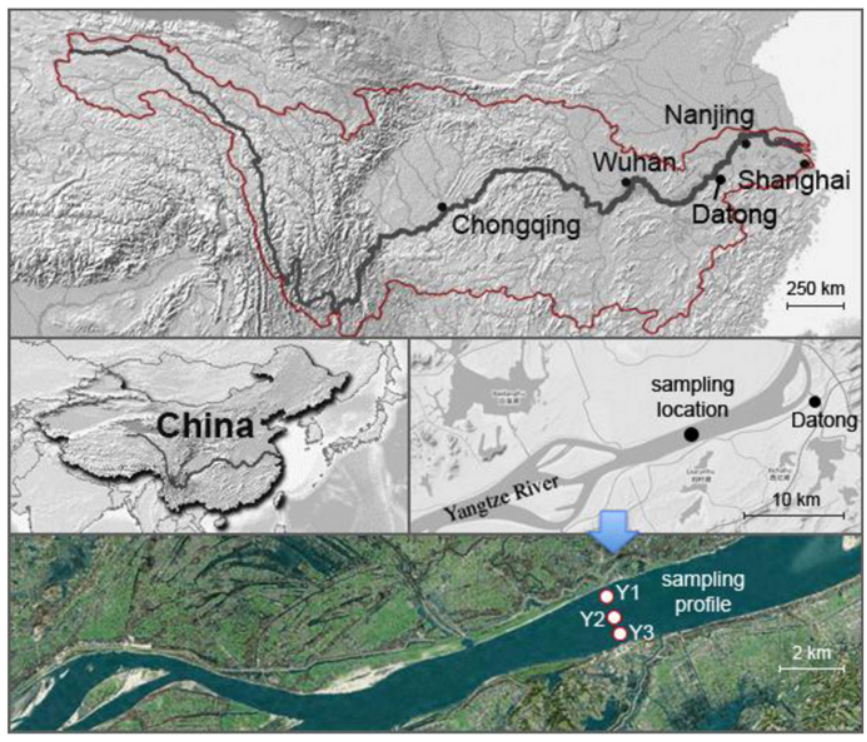

Fig. 1. Map of the Yangtze River and its catchment. The middle right map shows the sampling location across the river near Datong, and the bottom map illustrates the three sampling sites across the river ( $\mathrm{Y} 1, \mathrm{Y} 2, \mathrm{Y} 3)$.

$30^{\circ} 4611, \mathrm{E} 117^{\circ} 3748$; Y3: $\mathrm{N} 30^{\circ} 4627, \mathrm{E} 117^{\circ} 3741$ ) at $0.5 \mathrm{~m}$ below the surface using a stainless steel sampler. Samples were placed in precombusted (at $450{ }^{\circ} \mathrm{C}$ for 4 hours) $250 \mathrm{~mL}$ glass bottles (for analysis of pesticides, pharmaceuticals, and household chemicals) or $4 \mathrm{~L}$ precleaned brown glass bottles (for analysis of PAHs). For the PAHs analysis, a known volume $(4 \mathrm{~L})$ of the water samples was filtered through preweighed glass-fiber filters (Millipore, $0.7 \mu \mathrm{m}$ pore size, $142 \mathrm{~mm}$ diameter, preheated at $450{ }^{\circ} \mathrm{C}$ for 4 hours). The filtered particle fraction was weighted and stored at $-18^{\circ} \mathrm{C}$ for later analysis of the suspended particulate matter (SPM). The water samples for the analysis of pesticides, pharmaceuticals, and household chemicals were filtered through glass-fiber filters (Whatman, $0.7 \mu \mathrm{m}$ pore size, $47 \mathrm{~mm}$ diameter), and an isotope-labeled internal standard (IS) solution was added before storage. The concentrations in the three samples (Y1, Y2 and Y3) were initially analyzed individually. The corresponding results were in agreement, indicating that the river was well mixed at the sampling location. Hence, for reasons of efficiency we decided to mix the three samples before analysis.

\subsection{Analysis of $D O C$ and $P O C$}

The determination of DOC was performed by combustion with a Shimadzu TOC-5000A total organic carbon analyzer. TOC was determined on the glass-fiber filters by thermic combustion after treatment with $3 \mathrm{M} \mathrm{HCl}$. The blanks for each parameter were always below the limit of detection of $0.5 \mathrm{mg} / \mathrm{L}$.

\subsection{PAH analysis}

After spiking the surrogate standards, $4 \mathrm{~L}$ of the filtered water samples were passed through a C18 cartridge (Supelco) for extraction. The PAHs were then eluted with a $10 \mathrm{~mL}$ mixture of 1:9 hexane and dichloromethane followed by $5 \mathrm{~mL}$ of hexane. Following freeze-drying and weighing, the samples of suspended particulate matter were spiked with surrogate standards and extracted instrumentally by accelerated solvent extraction (ASE300, Dionex) with a mixture of 1:1 hexane and acetone for 10 minutes in two static cycles. The extraction temperature was $120{ }^{\circ} \mathrm{C}$, and the pressure was $1500 \mathrm{psi}$. The elution and extract of each sample was concentrated, solvent-changed, and purified with a 1:2 alumina-to-silica gel ratio as previously reported (Mai et al.,
2002). 2-fluorobiphenyl was added to the samples as an IS prior to instrumental analysis.

PAH concentrations were determined using an Agilent 7890A GC equipped with a $5975 \mathrm{C}$ mass selective detector under the selected ion monitoring mode. An HP-5 silica-fused capillary column $(60 \mathrm{~m} \times$ $0.32 \mathrm{~mm}$ inner diameter and $0.25 \mu \mathrm{m}$ film thickness) was used with helium as the carrier gas. The operation parameters were previously reported by Qiao et al. (2006). QA and QC procedures included analysis of method blanks, matrix duplicated spikes, and sample duplicates. The recoveries of acenaphthene-d10, phenanthrene-d 10 , chrysene-d 12 , and perylene-d12 for the water samples were $95 \pm 17 \%, 92 \pm 14 \%$, $86 \% \pm 17 \%, 72 \% \pm 24 \%$, respectively. Recovery rates for the samples of the suspended particulate matter were $88 \pm 21 \%$, $95 \pm 16 \%$, $105 \pm 27 \%$, $95 \pm 17 \%$, respectively. PAH concentrations were not corrected by the surrogate recovery data. The method detection limits (MDL) and relative standard deviation (RSD) for the PAHs were 3 to $7 \mathrm{ng} / \mathrm{L}$ and $0.4 \%$ to $10 \%$ in water samples, and 2 to $14 \mathrm{ng} / \mathrm{g}$ and $1 \%$ to $7 \%$ for the particulate samples.

\subsection{Analysis of pesticides, pharmaceuticals, and household chemicals}

The water samples were analyzed using a fully automated solid phase extraction (SPE) system, coupled directly to a liquid chromatography (LC) tandem mass spectrometer. The analytical method we used for applying 44 ISs for quantification has been reported elsewhere (Singer et al., 2010; Heeb et al., 2012). For targets where no structurally identical ISs were available, the ISs with the most similar retention times were used for quantification. The limit of quantification was determined from the analyte concentration, producing a signal-to-noise ratio of at least 10:1 in the matrix sample. The average relative recoveries were between $80 \%$ to $120 \%$ for all compounds except for imidacloprid (71\%) and metronidazole (65\%).

\section{Results and discussion}

\subsection{Organic carbon in water and suspended particles}

The DOC concentrations at Datong varied from $1.2 \mathrm{mg} / \mathrm{L}$ to $3.2 \mathrm{mg} / \mathrm{L}$ (Fig. 2), and the range compared well with previous measurements reported for the Yangtze River (Wu et al., 2007; Müller et al., 2008). During the dry season in the fall and winter, when water discharge can get as low as $12,000 \mathrm{~m}^{3} / \mathrm{s}$ (Fig. 2a), DOC concentrations were higher (Fig. 2b) and decreased during the wet season, when the water discharge was up to $50,000 \mathrm{~m}^{3} / \mathrm{s}$. The DOC load (shown as bars in Fig. 2b), however, was highest during the wet season. The POC levels (Fig. 2b) fluctuated in direct correlation to the concentration of the suspended particles (Fig. 2a and b). The POC content of the suspended particles, however, remained relatively constant at $1.9 \%$ to $3.1 \%$, indicating that the source of POC was mainly terrestrial (Sun et al., 2010; Xia and Zhang, 2011).

The ratio of DOC/POC varied from 0.67 to 5.17 with a median value of 1.75. The minimum value occurred during the flood season, and the maximum value occurred in the dry season. The DOC/POC ratio in $83 \%$ of the samples was more than 1, indicating that DOC was the dominant form of organic carbon (Xia and Zhang, 2011).

The estimated annual loads of DOC and POC were $1.7 \mathrm{Mt} / \mathrm{yr}$ and $1.3 \mathrm{Mt} / \mathrm{yr}$, respectively, which compared well with the 2009 annual flux estimated by Wang et al. (2012) (see Table 1). The decrease in the POC load from $8.5 \mathrm{Mt} / \mathrm{yr}$ in 1958 to 1984 (Wang et al., 1989) to $2.3 \mathrm{Mt} / \mathrm{yr}$ in 1998 (Duan et al., 2008) to $1.3 \mathrm{Mt} / \mathrm{yr}$ in 2013 is striking and can be attributed to the damming of the Yangtze. Uncertainties of flux estimations may be large, as POC loads depend on the loads of suspended particles, which show seasonal variability and hence depend on the sampling frequency. The extremely high DOC load of $5.4 \mathrm{Mt} / \mathrm{yr}$ in 1998 to 1999 was caused by an unusually severe flood during this time. 

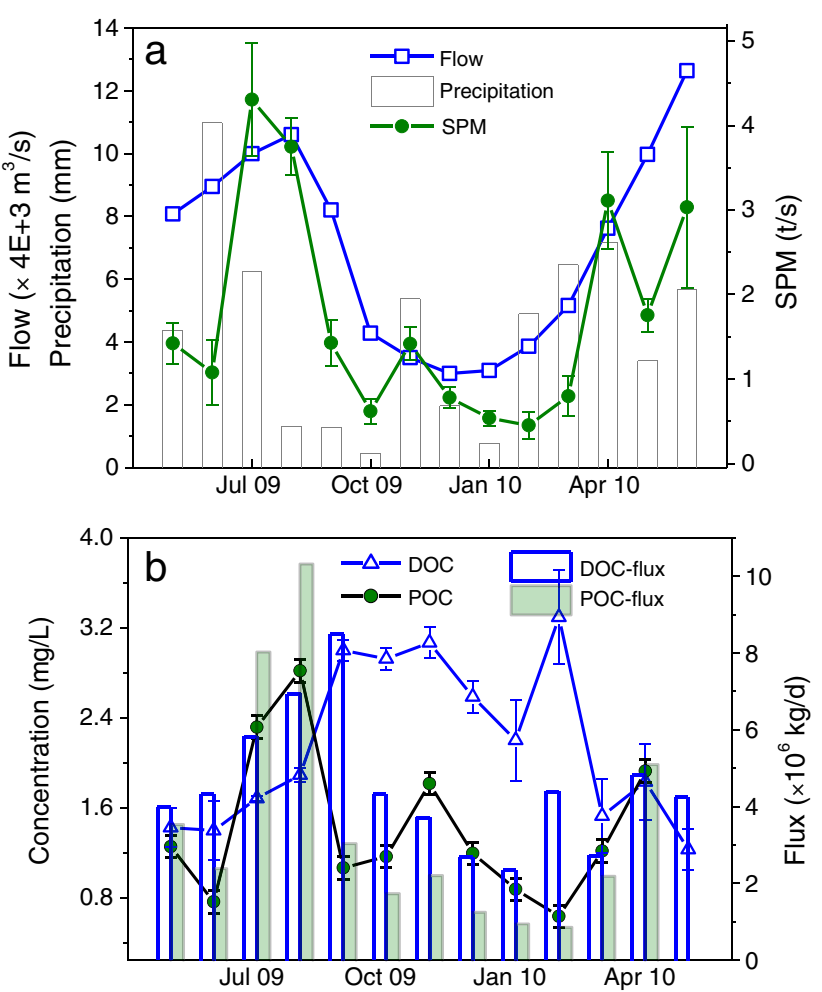

Fig. 2. (a) Monthly river water discharge, precipitation in Anqing (60 km upstream of Datong), and load of suspended particulate matter (SPM); (b) Monthly dissolved organic carbon (DOC) and particulate organic carbon (POC) concentrations and fluxes at Datong station from May 2009 to June 2010

\subsection{Household chemicals and pharmaceuticals}

The following household chemicals were targeted in the filtered samples: 2-Naphtalenesulfonic acid, benzotriazole, 4-/5-methylbenzotriazole, acesulfam, caffeine, N,N-Diethyl-3-methylbenzamide (DEET) and sucralose. Only caffeine (15-157 ng/L), sucralose (120-430 ng/L), DEET (4-16 ng/L), benzotriazole (19-67 ng/L), 4-/ 5-methyl-benzotriazole (7-29 $\mathrm{ng} / \mathrm{L})$, and climbazole (3-4 ng/L) were detected in some of the samples (see Fig. 3 and Table S1). The sweetener sucralose occurred in the highest concentration (an average of $217 \mathrm{ng} / \mathrm{L}$ ) out of all household chemicals screened in this study. The high sucralose concentrations come from the diet of the people in the south of China, who prefer sweetened food. The persistence of sucralose in wastewater treatment plants (WWTPs) and the aquatic environment (Mead et al., 2009; Torres et al., 2011) was another reason for the high sucralose in the river. The load of sucralose in the Yangtze River amounted to $169 \mathrm{t} / \mathrm{yr}$, representing $85 \%$ of the sucralose consumption in China (200 t/yr).

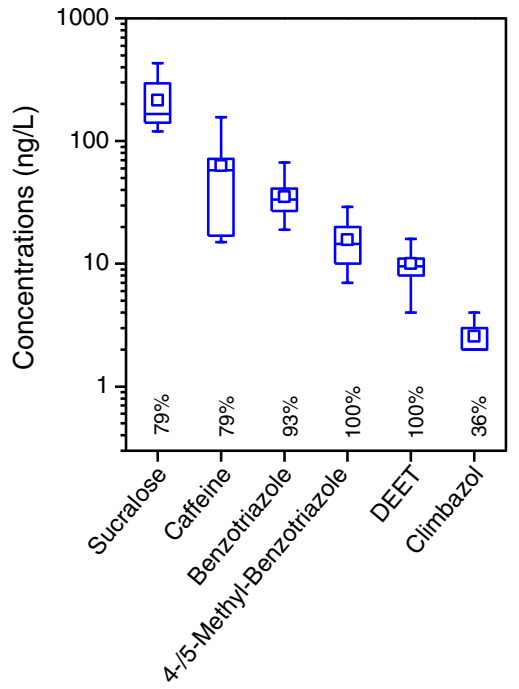

Fig. 3. Concentrations of anthropogenic substances in the Yangtze River at Datong station (only the results higher than LOQ are plotted). Boxes indicate the range between the 25th and 75th percentiles. The whiskers extend from the edge of the box to the minimum and maximum data values. The horizontal line and the square inside indicate the median value and the mean value, respectively. Additional data are provided in Table S1.

\subsubsection{Sucralose}

The artificial sweetener sucralose has previously been used as an indicator of domestic wastewater loading to surface waters. Heeb et al. (2012) reported an average sucralose concentration of $2.6 \mu \mathrm{g} / \mathrm{L}$ in WWTP effluents in Beijing, China. Recently, Tollefsen et al. (2012) reviewed published studies for the presence, fate, and effects of sucralose in the aquatic environment and estimated an average concentration of sucralose in wastewater in the range of 0.4 to $11 \mu \mathrm{g} / \mathrm{L}$ (and up to $119 \mu \mathrm{g} / \mathrm{L}$ ). Assuming that the sucralose level in the sewage effluents of southern China was in the range of around $10 \mu \mathrm{g} / \mathrm{L}$, our determined total annual load of $169 \mathrm{t}$ of sucralose in the Yangtze River would correspond to a wastewater discharge of about 47 Mio $\mathrm{m}^{3} / \mathrm{d}$ (or 17 billion $\mathrm{m}^{3} /$ year) of wastewater into the Yangtze River. This signifies that during the dry season, up to $5 \%$ of the Yangtze water consists of sewage. Using the number for per-capita water consumption in southern China of 180 L per day in 2010 reported by the National Bureau of Statistics (NBSC, 2010), we estimate that the Yangtze transports the sewage of about 270 million people. This estimation could be improved if sewage effluent concentrations were known. However, even though the present assumption is very rough, it results in an estimate for the population that lies in the same order of magnitude as the estimated population in the catchment (approximately 400 million).

\subsubsection{Caffeine}

The concentration range of caffeine in the Yangtze was 15 to $157 \mathrm{ng} / \mathrm{L}$ (Fig. 3), which was higher than the Mississippi River (0-38 ng/L; Zhang et al., 2007) and lower than rivers downstream of Beijing (29-5000 ng/L;

Table 1

Dissolved and particulate annual loads of organic carbon in the Yangtze River.

\begin{tabular}{|c|c|c|c|c|c|c|c|c|}
\hline \multirow{2}{*}{$\begin{array}{l}\text { Sampling } \\
\text { site }\end{array}$} & Distance to estuary & Time & Water discharge & DOC & POC & DOC load & POC load & Reference \\
\hline & $\mathrm{km}$ & & $\times 10^{3} \mathrm{~m}^{3} / \mathrm{s}$ & $\mathrm{mg} / \mathrm{L}$ & $\mathrm{mg} / \mathrm{L}$ & $\mathrm{kt} / \mathrm{yr}$ & $\mathrm{kt} / \mathrm{yr}$ & \\
\hline Datong Station & 525 & 1958-1984 & & 3.4 & & 2980 & 8500 & Wang et al. (1989) \\
\hline Inner estuary & & Jan.-Jul. 1986 & 28 & & & 1800 & $4500-6000$ & Cauwet and Mackenzie (1993) \\
\hline Nantong & 188 & 1997 (bimonthly) & $25-31$ & 1.26 & & 900 & 2200 & Wu et al. (2007) \\
\hline Datong Station & 525 & 1998-1999 (bimonthly) & $10-75$ & $2.6-6.1$ & $0.4-3.0$ & 5405 & 2279 & Duan et al. (2008) \\
\hline Datong Station & 525 & 2009 (monthly) & $12-40$ & $1.6-2.7$ & $0.6-3.6$ & 1580 & 1520 & Wang et al. (2012) \\
\hline Datong Station & 525 & 2009-2010 (monthly) & $12-51$ & $0.9-3.1$ & $0.6-2.8$ & 1660 & 1270 & this study \\
\hline
\end{tabular}


Heeb et al., 2012) and the rivers of the Pearl River Delta (15-865 ng/L, Yang et al., 2013). Caffeine is removed efficiently by WWTPs (more than $85 \%$ ) and can be degraded in the natural environment (Buerge et al., 2003; Sui et al., 2010). Therefore, caffeine can be used as a molecular tracer for the efficiency of WWTPs (Buerge et al., 2003; Standley et al., 2000). Hence, higher loads of caffeine in the river may indicate higher wastewater input and/or lower wastewater treatment efficiency. During our 14-months of monitoring the Yangtze, the monthly load of caffeine was higher during the wet season (i.e., June and July; Fig. 4), indicating either that the capacity of WWTPs were exceeded due to precipitation or that the amount and type of caffeine-containing beverages consumed depended on the season (e.g., tea with varying caffeine levels).

\subsubsection{Benzotriazole}

Benzotriazole (BT) and 4-/5-methyl-benzotriazole (MBT) are "emerging contaminants" that are used as corrosion inhibitors in WWTPs' effluent and receiving waters (Voutsa et al., 2006; Giger et al., 2006; Reemtsma et al., 2010). They can only be partly removed from wastewater during the treatment process (23\%-85\%) and have high stability in surface waters (Giger et al., 2006; Reemtsma et al., 2010; Kahle et al., 2009; Heeb et al., 2012). In this study, BT and MBT occurred in the Yangtze River in concentration ranges of 19 to $67 \mathrm{ng} / \mathrm{L}$ and 7 to $29 \mathrm{ng} / \mathrm{L}$, respectively (Fig. 3). Temporally, the highest loads of BT and MBT were measured in August 2009 (7.2 t/month) and May 2010 (1.8 t/month) (Fig. S1). Usually, winter temperatures in southern China stay above zero degrees, resulting in a much smaller consumption of aircraft de-icing fluid and motor vehicle antifreeze, which both contain BT and MBT, as compared to northern China and Europe. Thus, BT and MBT in the Yangtze was possibly mainly influenced by wastewater input in the basin.

\subsubsection{Pharmaceuticals}

We also investigated the occurrence and loads of 43 pharmaceutical substances, including antibiotics, $\beta$-blockers, analgetics, lipid regulators, and antiepileptic drugs. Some commonly consumed antibiotics and analgesics in China, including sulfamethoxazole, sulfadiazine,

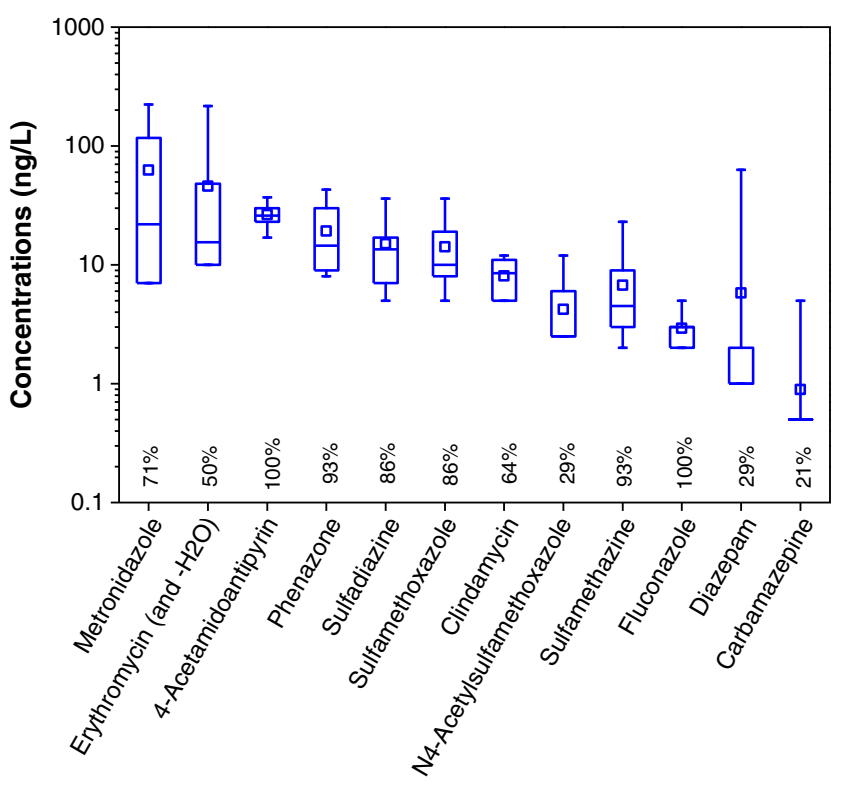

Fig. 5. Concentrations of pharmaceuticals and other anthropogenic substances in the Yangtze River at Datong station (only the results higher than LOQ are plotted). The statistical definition of the boxes is described in the caption of Fig. 3. The values at the bottom of the graph show the percentage of positive findings among all analyzed samples. Additional data are provided in Table S1.

sulfamethazine, erythromycin, 4-acetamidoantipyrin (the metabolite of metamizole), phenazone, and metronidazole, were detected in most samples (Fig. 5). Fluconazole (dermatologicals), sulfamethazine, sulfamethoxazole, phenazone, 4-acetamidoantipyrin (metabolite of metamizole), and sulfadiazine were compounds with high detection frequency (more than $85 \%$ ). Other pharmaceuticals, such as atonolol, metoprolol, and sotalol ( $\beta$-blockers), bezafibrate (a lipid regulator), hydrochlorothiazid (a an diuretic), lidocaine (anesthetic), mefenamic acid (an anti-inflammatory), and sulfapyridine and trimetoprim (antiinfectives) were not detected or were below their limit of quantification
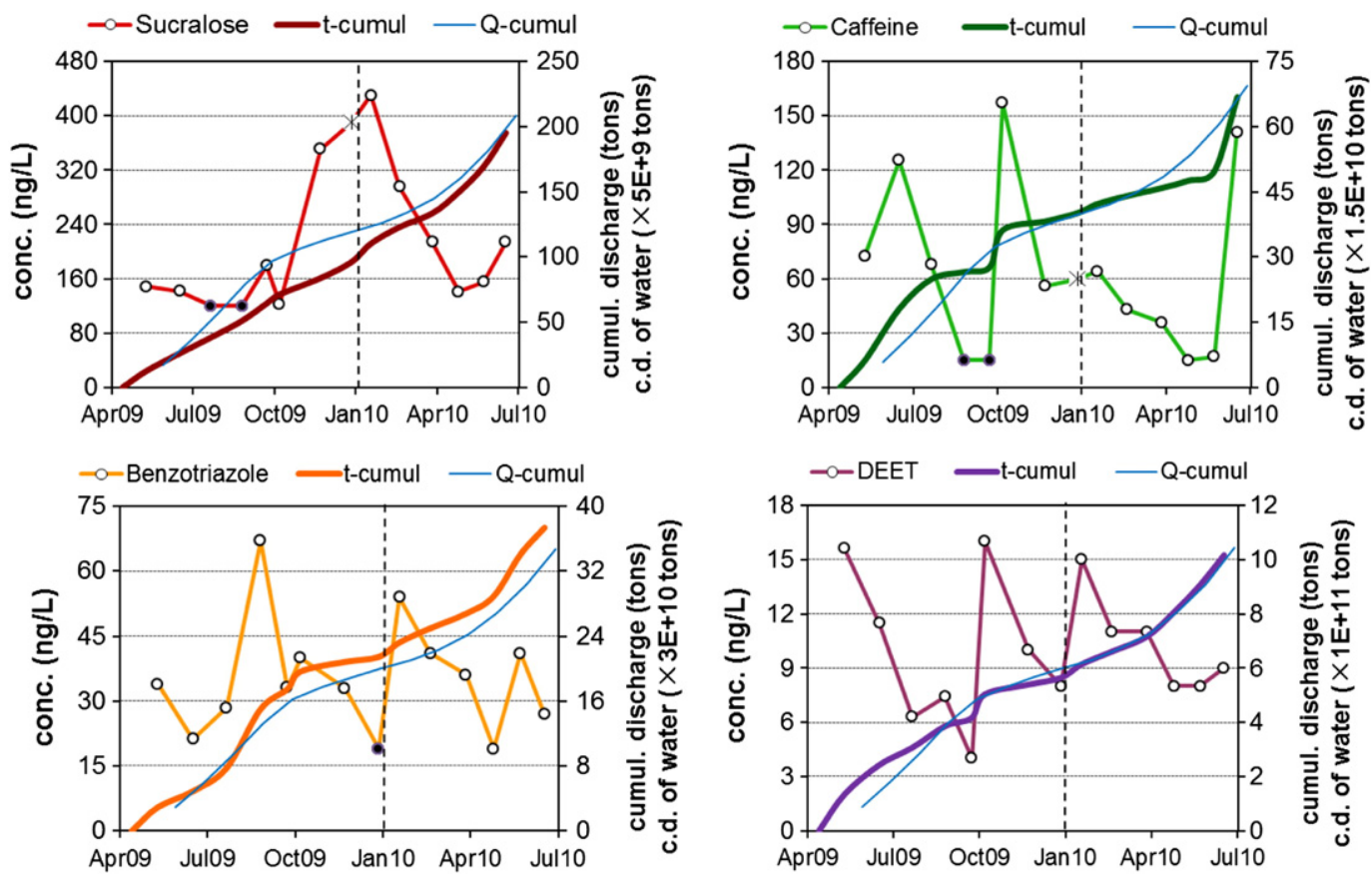

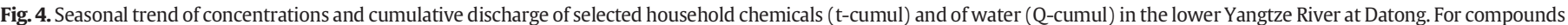

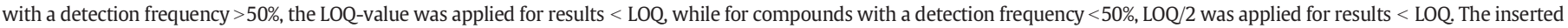

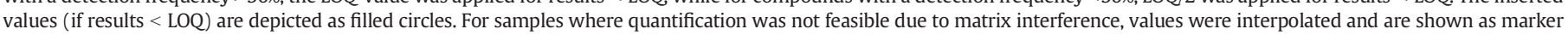
asterisks. Additional data are provided in Appendix 1. 
(LOQ). As can be seen in Fig. 5, the concentrations of detected pharmaceuticals in most samples were below $50 \mathrm{ng} / \mathrm{L}$ except for the antibiotics metronidazole and erythromycin (and $-\mathrm{H}_{2} \mathrm{O}$ ). The concentrations of metronidazole ranged from $7 \mathrm{ng} / \mathrm{L}$ to $224 \mathrm{ng} / \mathrm{L}$ with the average value of $74 \mathrm{ng} / \mathrm{L}$, and the concentrations of erythromycin (and $-\mathrm{H}_{2} \mathrm{O}$ ) ranged from $21 \mathrm{ng} / \mathrm{L}$ to $217 \mathrm{ng} / \mathrm{L}$ with an average value of $81 \mathrm{ng} / \mathrm{L}$ (Fig. 5, Table S1).

Very few analyses of pharmaceuticals have been published for the Yangtze River to date. Y. Yang et al. (2011) reported the detection of selected pharmaceuticals, and Yan et al. (2013) reported the occurrence and distribution of 20 antibiotics in the surface water of the Yangtze Estuary. Y. Yang et al. (2011) found sulfamethoxazole, tamoxifen, and indomethacine with concentrations of more than $100 \mathrm{ng} / \mathrm{L}$. The concentrations of sulfamethoxazole and carbamazepine detected in this study at Datong station were approximately 10 times lower than the concentrations further downstream in the estuary. Compared with Yang et al.'s results, the concentrations of sulfonamides (sulfadiazine, sulfamethoxazole, and sulfamethazine) in our study were 1 to 3 times lower. This supports the assumption of Y. Yang et al. (2011) that WWTPs are the main sources of pharmaceuticals in the Yangtze River estuary. Hence, estimating the pollutant load is necessary for the assessment of the water quality in the estuary, which receives both the input from the river and the discharge from WWTPs along the coastal area.

Pharmaceuticals in the water samples displayed seasonal variations during the 14 months of our monitoring period (Fig. 6). The antiinfective sulfamethoxazole (SFMX) had higher concentrations and loads in July and September (the wet season) of 2009 than in any other months (Fig. 6). Higher concentrations and loads of pharmaceuticals were also reported by Radke et al. (2010) in a German river during precipitation events and by Tamtam et al. (2008). The authors attributed the concentration peaks during precipitation events to the accelerated displacement of wastewater from the sewer system and the WWTP into the river at the beginning of a rain event and the decreased removal efficiency in the WWTP during periods of increased wastewater flow (Radke et al., 2010). This could explain the higher concentrations and loads of SFMX and sulfadiazine in the wet season in the Yangtze, although sampling with higher frequency would be necessary to study the dynamics and attenuation of the pharmaceuticals. In Yan's study (2013), higher concentrations of sulfonamides were found in January compared to other seasons in the Yangtze estuary. The authors attributed this feature to the low flow diluting the WWTPs inputs and the cold temperature inhibiting microbial degradation in January. In this study, some of the detected pharmaceuticals, including N4-acetylsulfamethoxazole (a metabolite of SFMX), diazepam, metronidazol, and diclofenac, showed higher concentrations in the winter. For example, diazepam was not detected in the summer, while its concentration was $63 \mathrm{ng} / \mathrm{L}$ in January 2010. In addition, sulfamethazine (SFMZ), 4-acetamidoantipyrine, and erythromycin (and $-\mathrm{H}_{2} \mathrm{O}$ ) showed higher concentrations and loads in the autumn and spring (Fig. 6).

\subsection{PAHs in water and suspended particulate matter}

PAHs are primarily produced by incomplete combustion of wood, petroleum, and coal and are emitted from coke ovens, automobile exhaust, or heat and power generation. Some PAH compounds have been found to be mutagenic and carcinogenic (Harvey, 1991; Nielsen, 1996). We detected a total of 16 PAHs ranging from 130 to $380 \mathrm{ng} / \mathrm{L}$ in water (mainly Nap, Ace, Fl, and Phe) and from 1830 to 9150 ng/g in SPM with the predominance of Fl, Ace, Fluo, and Pyr (Table 2, Fig. S2).

PAH concentrations have been previously reported in different sections of the Yangtze (Table 2), such as 240 to $620 \mathrm{ng} / \mathrm{L}$ in the Wuhan section in July 2005 (C.L. Feng et al., 2007), an average of $5260 \mathrm{ng} / \mathrm{L}$ at Nanjing in January 2007 (Wu et al., 2009), and 10 to $3580 \mathrm{ng} / \mathrm{L}$ in the Jiangsu section (He et al., 2011). The level of dissolved PAHs from our study at Datong station (located right between the Wuhan and the
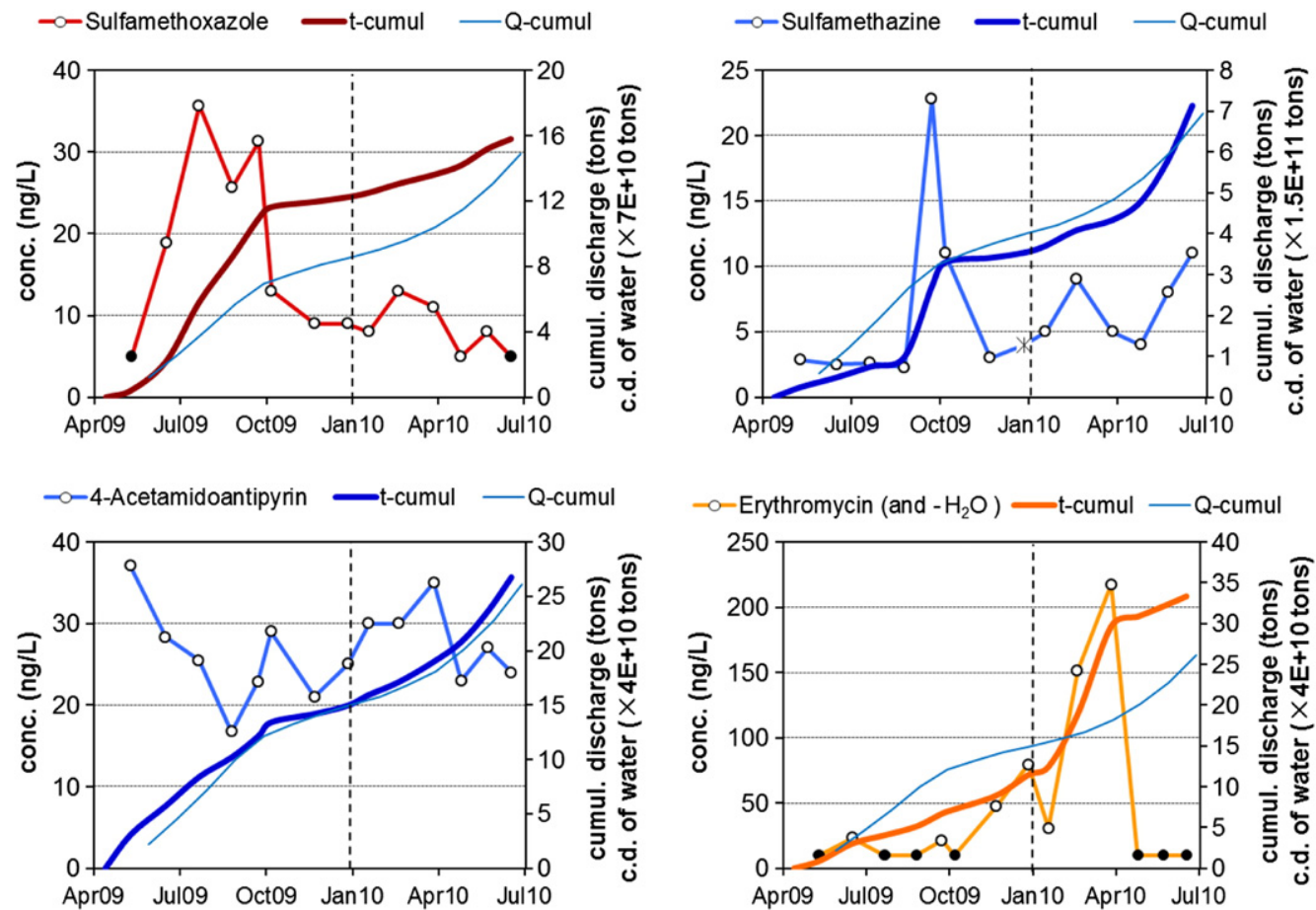

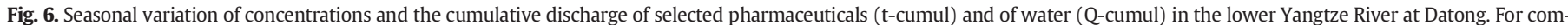

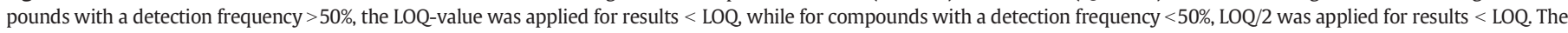

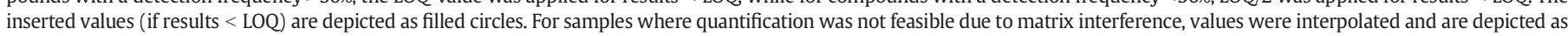
marker asterisks. Additional data are provided in Appendix 1. 
Table 2

Concentrations of PAHs in water (ng/L) and SPM (ng/g) of the Yangtze River.

\begin{tabular}{|c|c|c|c|c|}
\hline location & sampling medium & sampling time & Concentrations (ng/L, ng/g) & Reference \\
\hline Wuhan reach & water & Jul. 2005 & 874 (median) & C.L. Feng et al. (2007) \\
\hline Datong Station & water & $2009-2010$ & $130-380$ & this study \\
\hline Nanjing reach & water + SPM & Jan. 2007 & 5260 (average) & Wu et al. (2009) \\
\hline Jiangsu reach & water & Sep. 2004;jan. 2005 & $10-3580$ & He et al. (2011) \\
\hline River & SPM & Nov. 2006 & $<700-48580$ & Müller et al. (2008) \\
\hline Wuhan reach & sediments & Jul. 2005 & $30-4000$ & C.L. Feng et al. (2007) \\
\hline Wuhan reach & sediments & Dec. 2005 & $70-1210$ & C.L. Feng et al. (2007) \\
\hline Wuhan reach & SPM & Jul. 2005 & $4290-5000$ & C.L. Feng et al. (2007) \\
\hline Wuhan reach & SPM & Dec. 2005 & $950-15350$ & C.L. Feng et al. (2007) \\
\hline Datong Station & SPM & May 2009-Jun. 2010 & $1830-9150$ & this study \\
\hline Estuary & sediment core & Sep. 1996 & $80-11740$ & Liu et al. (2000) \\
\hline Estuary & sediment core & Jul. 1998 & $10-2370$ & Xu et al. (2001) \\
\hline Estuary & sediments & Apr. 2004 & $850-620$ & Hui et al. (2009) \\
\hline
\end{tabular}

a Surface water samples without filtration were extracted for PAHs using liquid-liquid extraction.

Nanjing section) ranged 320 to $630 \mathrm{ng} / \mathrm{L}$ and was about one order of magnitude lower compared to the data from Nanjing from 2005 and 2007 (Table 2). The comparison among individual PAHs had similar results to the comparison among total PAHs. This may be explained by the three following factors. Firstly, the anthropogenic discharge of PAHs from big cities is generally larger than that from areas with a lower population density (Xu et al., 2006). The population density of Anhui province where the Datong station is located is only half of the populations of the Jiangsu and Hubei provinces (Table S2). Secondly, the percentage of households connected to WWTPs in Anhui province (91\%) is higher than in other provinces of the Yangtze Basin (Table S2). Lastly, resuspension of PAHs downstream of the Datong station might be influenced by the tide (J.L. Feng et al., 2007) and could thus increase the PAH concentrations in the surface water.

The loads of both dissolved and particulate PAHs were higher in the wet season (9.3-12.0 and 9.2-12.9 t/month, respectively) than in the dry season (3.7-6.3 and 3.6-6.7 t/month, respectively) (Fig. 7). The flux of PAHs may have been increased due to higher atmospheric inputs from wet deposition and runoff in the wet season compared to the dry season, although the concentration levels were slightly decreased due to dilution in the wet season (Fig. 7). For some PAHs, such as phenathrene, which also has a biogenic source, the concentration was higher in the early wet season than the other seasons (Fig. 7) and could be also caused by runoff from soil. Due to the high flow rate, the annual flux of the total 16 PAHs at Datong station was some 370 tons. This corresponds to $30 \%$ of all PAHs emitted in Anhui province, or $4 \%$ of the whole Yangtze Basin (these data were compiled by $\mathrm{Xu}$ et al., 2006), if all emissions in 2010 were equal to the 2004 emissions.

\subsection{Pesticides}

A total of 51 compounds, including 2,4-D, atrazine, bentazon, diuron, metazochlor, terbutryn, and azoxystrobin, were quantified in the Yangtze water samples. Only eight were detected with an LOQ of 1 to $10 \mathrm{ng} / \mathrm{L}$ (Fig. 8). Our results were similar to the findings by Müller et al. (2008). The mean concentrations of pesticides in most of the samples analyzed in this study were below $30 \mathrm{ng} / \mathrm{L}$ except for atrazine-
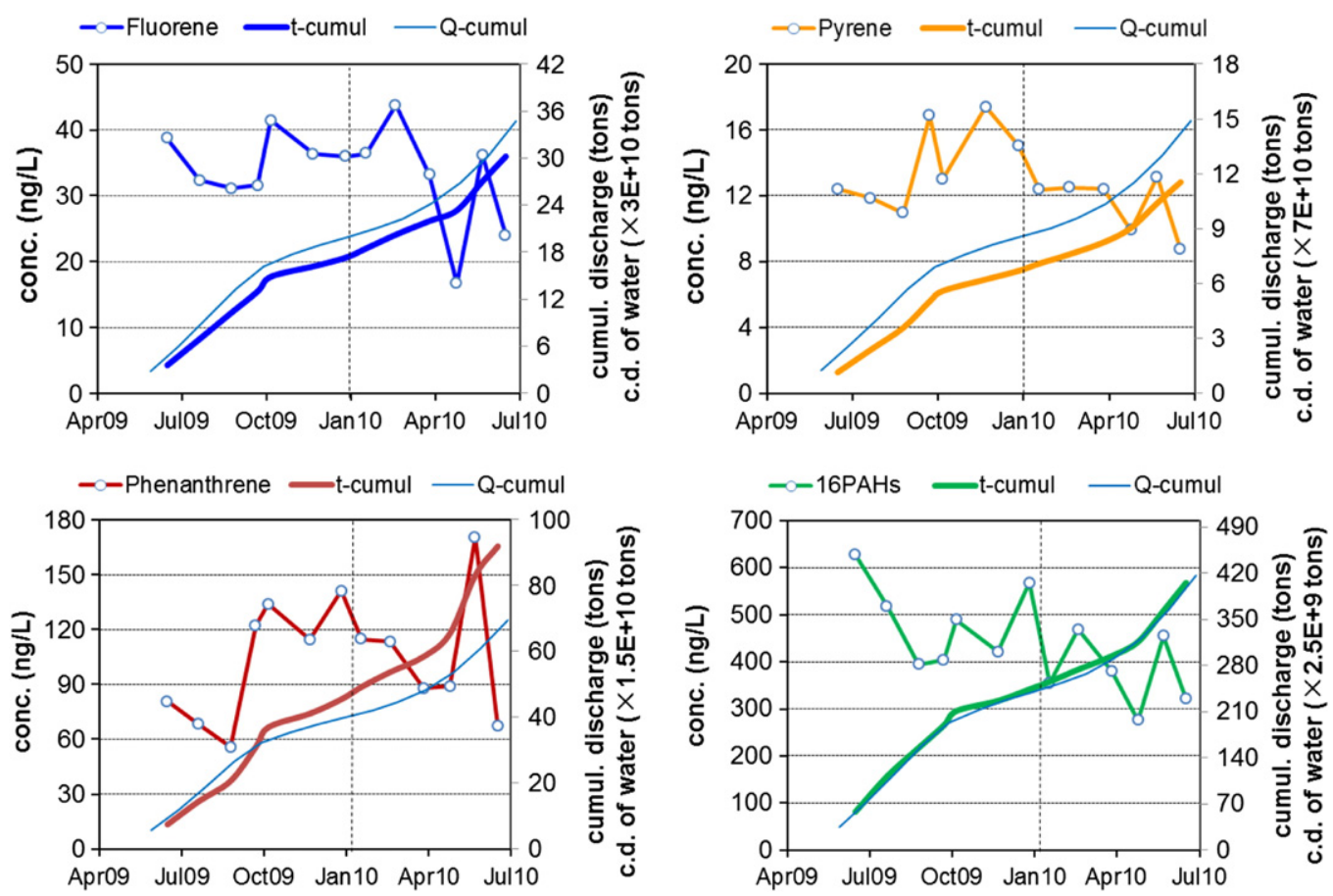

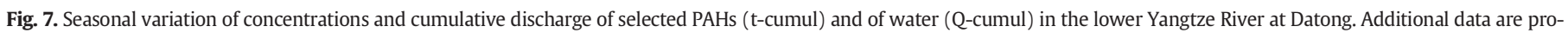
vided in Appendix 1. 


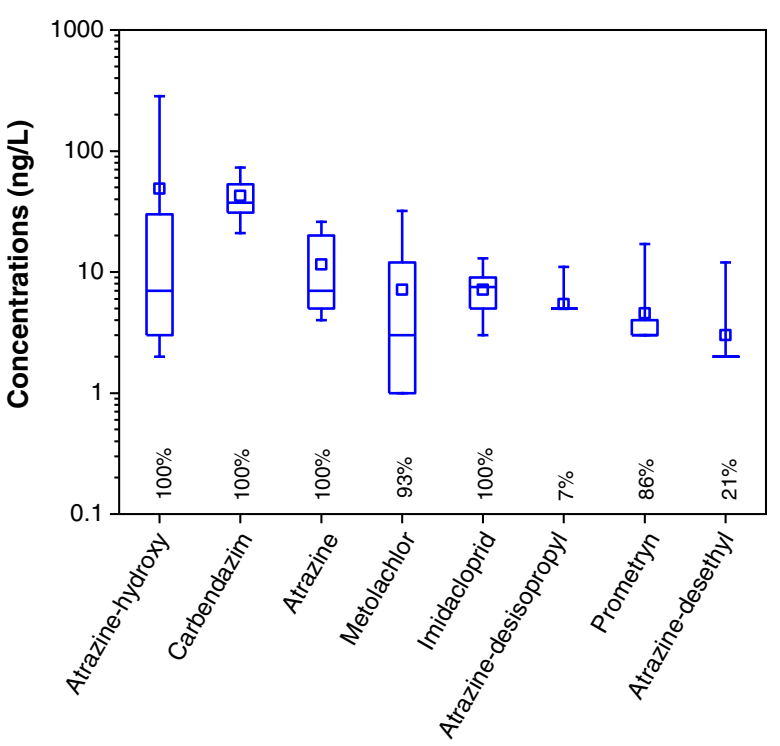

Fig. 8. Concentrations of pesticides and metabolites in the Yangtze River at Datong station (only results > LOQ are plotted). The statistical definition of the boxes is described in the caption of Fig. 3. The values at the bottom of the graph show the percentage of positive findings among all analyzed samples. Additional data are provided in Table S1.

hydroxy (HA; a metabolite of atrazine) and carbendazim, with average concentrations of $45 \mathrm{ng} / \mathrm{L}$ and $43 \mathrm{ng} / \mathrm{L}$, respectively. HA occurred in the samples with a maximum concentration of $284 \mathrm{ng} / \mathrm{L}$ in January 2010 and a minimum concentration close to the LOQ $(2 \mathrm{ng} / \mathrm{L})$. The concentrations were similar to those reported by Gfrerrer et al. (2002), who detected atrazine (1.0-18.3 ng/L) without metabolites (the authors only analyzed atrazine-desethyl and atrazine-desisopropyl, not HA) in surface water from the Yangtze, peaking in May. As the main crop type in the Yangtze basin is rice (66\% of all crops, Table $\mathrm{S} 2$ ), which is not tolerant to atrazine like corn, the levels of atrazine and its metabolites were generally much lower than those in other large rivers of the world (Clark et al., 1999; Liu et al., 2002).

The loads of most pesticides, such as atrazine, carbendazim, metolachlor, prometryn, and imidacloprid, were higher in summer (Fig. 9) as a result of higher application. The highest combined monthly loads of carbedazim, atrazine, prometryn, metolachlor, and imidacloprid were 5730, 2420,1710, 1770 and $1350 \mathrm{~kg} / \mathrm{month}$ in August 2009, June 2010, July 2009, May 2010, and August 2009, respectively. In addition, the load of metolachlor was also high in October 2009 (1740 kg/month) when the water discharge was much lower than in summer. The load of atrazine and its metabolite HA also fluctuated in autumn and winter when the river water flow was the lowest of the studied period. This pattern suggests additional use of atrazine and metolachlor during the autumn and winter, which may be due to pesticide use for winter crops (wheat) and vegetables.

The occurrence of atrazine degradation products may be related to several factors, such as the season, the transformation products formed in the soil, or dilution by runoff. Obviously, HA was the predominant metabolite present at Datong station. Atrazine-desethyl (DEA) was detected in only 3 samples at levels between 4 to $12 \mathrm{ng} / \mathrm{L}$, and atrazinedesisopropyl was detected in only one sample (see Table S1). DEA has been reported to be one of the most prevalent degradation products in bulk soil (Panshin et al., 2000), and its prevalence in rivers mainly happens shortly after the application of atrazine. This may explain the low detection frequency of DEA in this study. The prevalence of HA was also found in other watersheds like Missouri streams, although it is the least mobile degradation product (Lerch et al., 1995, 1998). The high winter concentration of HA in the Yangtze River was possibly caused by enhanced direct photolysis of atrazine due to lower water
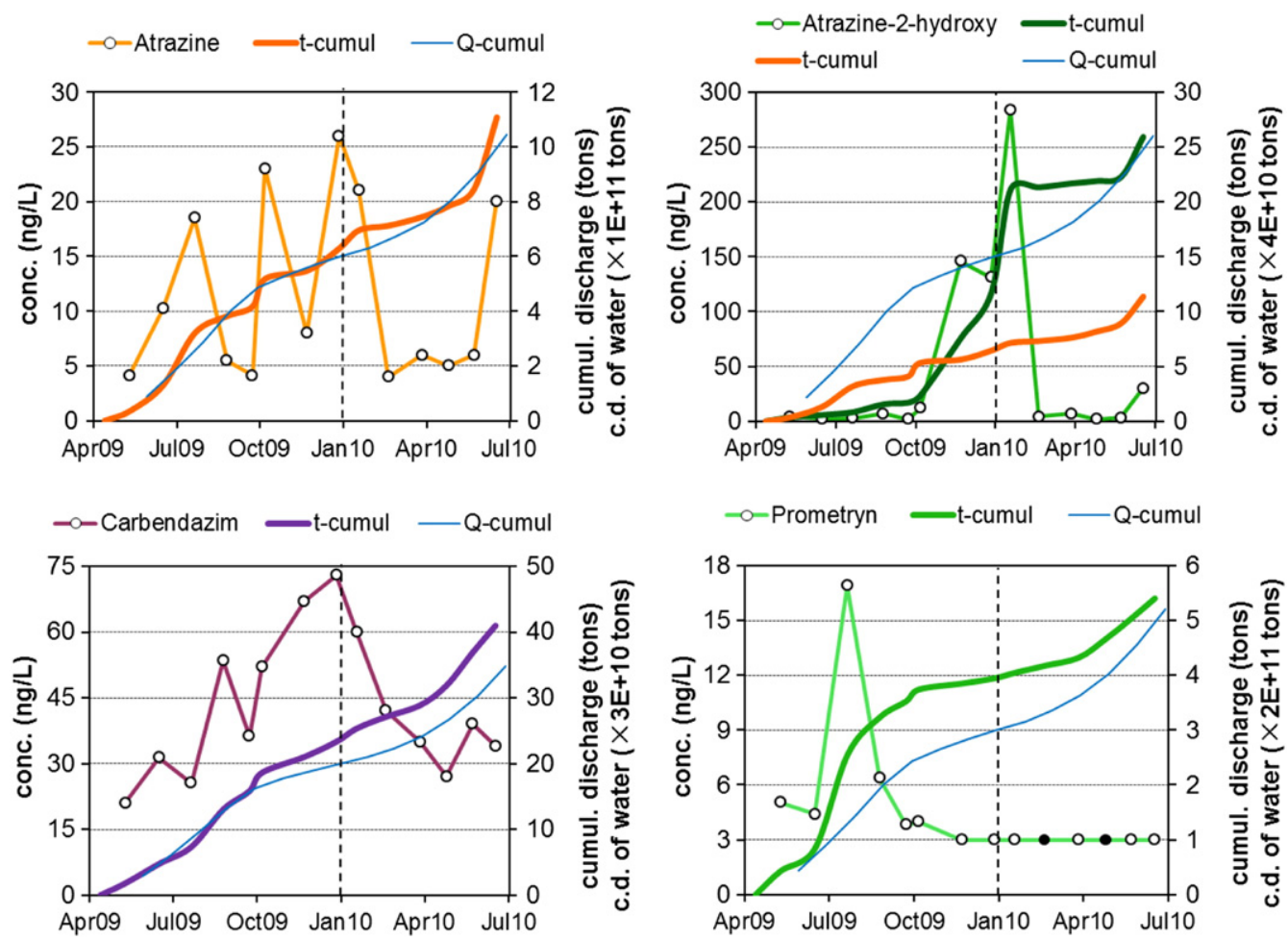

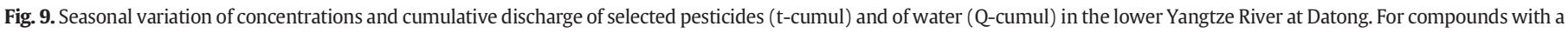

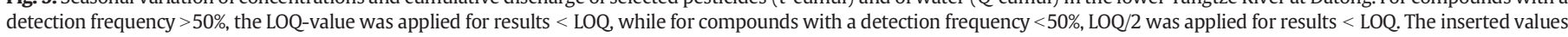
(if results $<$ LOQ) are depicted as filled circles. Additional data are provided in Appendix 1. 
turbidity in the winter months (Fig. S3). This phenomenon was also observed by Steen et al. (2000) in the Scheldt estuary.

\subsection{Comparison of pollutant loads with other large rivers}

As the discharge of the Yangtze ( $900 \mathrm{~km}^{3} / \mathrm{yr}$ ) is the third largest in the world after the Amazon (6930 km³ $/ \mathrm{yr}$ ) and Congo Rivers (1410 km³/yr), the loads of micropollutants are large in spite of low concentration levels (Table S1). The total annual loads of organic micropollutants in the lower Yangtze at Datong amounted to approximately $890 \mathrm{t}$, consisting of $273 \mathrm{t}$ household chemicals, $152 \mathrm{t}$ pharmaceuticals and metabolites, $98 \mathrm{t}$ pesticides and metabolites, and $370 \mathrm{t}$ PAHs (see Appendix 1). It should be noted that volatilization, sorption, degradation, and, transformation can lead to natural removal of organic pollutants in the river (Gioia and Dachs, 2012). Such attenuation processes could reduce the load of organic pollutants discharged by the Yangtze River to the East China Sea.

About $60 \%$ of the load of household chemicals in the Yangtze consisted of the sweetener sucralose. The per-capita load of sucralose would be $0.77 \mathrm{~g} / \mathrm{year}$ based on the assumed concentration in wastewater $(10 \mu \mathrm{g} / \mathrm{L})$ and wastewater discharge $\left(47 \mathrm{Mio} \mathrm{m}^{3} / \mathrm{d}\right)$ in the Yangtze Basin. This result was smaller compared to the United States, where sucralose is used more frequently and concentrations of sucralose in WWTP effluents can reach up to $27 \mu \mathrm{g} / \mathrm{L}$ (Oppenheimer et al., 2011) and $120 \mu \mathrm{g} / \mathrm{L}$ (Mead et al., 2009).

Antibiotics (110 t/yr) contributed $74 \%$ of the load of pharmaceuticals (152 t/yr) in the Yangtze. In comparison, antibiotics in the Haihe Basin downstream Beijing City (0.74 t/yr) contributed only 20\% of the pharmaceuticals and metabolites loads (Heeb et al., 2012).

Carbendazim and atrazine, including its metabolites, accounted for $81 \%$ of the load of pesticides. As discussed above, due to the different crop patterns, the load of atrazine and its metabolites (43 t/yr) was considerably lower than in European and American rivers in the 1990s, when large amounts of herbicides were applied on field crops; e.g., the Mississippi River (640 t/yr, Clark et al., 1999), which has a water discharge rate that is similar to the Yangtze River.

\section{Conclusions}

Based on our 14-month survey, we present the first comprehensive assessment of concentrations and annual loads of a broad range of micropollutants in the Yangtze River. Most of the investigated compounds were below concentrations of $200 \mathrm{ng} / \mathrm{L}$, mainly due to the enormous dilution by the large water discharge. However, the pollutant loads are large (Appendix 1), and they may have significant effects on the ecosystem of the receiving shelf area of the East China Sea. The loads of most pesticides, anti-infectives, and PAHs were higher in the wet than in the dry season. This was attributed to increased agricultural application of chemicals in the summer, elevated water discharge through the sewer systems and WWTPs as a result of high hydraulic loads and the related lower treatment efficiency, and seasonally increased deposition from the atmosphere and runoff from the catchment. The state-of-the-art analytical methods used in this study allowed for the quantification of 268 compounds. However, one has to keep in mind that many more are likely to be present in the river as thousands of organic chemicals are used in almost any application and product of the modern lifestyle. We found that the huge load of $8,200 \mathrm{t} /$ day of organic carbon, when combined with the nutrient discharge of 4,400 t/day of nitrogen and 290 t/day of phosphorus (Müller et al., 2012), significantly contributes to the eutrophication and algal blooms along the coast of the East China Sea.

The investigated cross-section at Datong proved to be an ideal study site to assess the integral discharge of pollutants from the 400 million inhabitants living in the Yangtze Basin. This is particularly due to the fact that the river is not yet tidal at Datong and that the river water is well mixed because the last $50-\mathrm{km}$ river section upstream Datong is barely populated and wastewater discharge to the river is therefore negligible. We hence suggest that the authorities consider this location in their planning to expand the Chinese river monitoring network with advanced chemical and physical analyses.

\section{Conflict of interest}

The authors declare no competing financial interest.

\section{Acknowledgments}

We thank Hongliang Sha at the Datong Station for excellent assistance in our sampling campaigns, Philippe Longrée and Florian Heeb for the screening of initial samples, and Falk Dorusch and Alfred Lück for laboratory assistance. We gratefully acknowledge the helpful comments and observations of three anonymous reviewers. This study was funded by the External Cooperation Program of the Chinese Academy of Sciences, Grant No. GJHZ0908, and by the Sino-Swiss Science and Technology Cooperation Program of the Swiss State Secretariat for Education and Research, Project No. IZL CZ2 123912 and the ETH Zurich.

Appendix 1. Annual loads of micropollutants determined in the lower Yangtze River at Datong (from July 2009 to June 2010). For compounds with detection frequency $>50 \%$, the LOQ-value was applied for the calculation of loads, while for compounds with detection frequency $<50 \%, \mathrm{LOQ} / 2$ was applied. For samples where quantification was not feasible due to matrix interference, values were interpolated and used for load calculation.

\begin{tabular}{|c|c|c|c|}
\hline Pharmaceuticals & $\begin{array}{l}\text { annual load } \\
\text { (t/yr) }\end{array}$ & PAHs & $\begin{array}{l}\text { annual load } \\
\text { (t/yr) }\end{array}$ \\
\hline Sulfamethoxazole & 13.6 & Nap & 168.8 \\
\hline N4-Acetylsulfamethoxazole & 3.2 & Acy & 4.3 \\
\hline Clindamycin & 6.6 & Ace & 10.3 \\
\hline Sulfadiazine & 12.5 & $\mathrm{Fl}$ & 27.5 \\
\hline Sulfamethazine & 6.6 & Phe & 84.5 \\
\hline Erythromycin (and $-\mathrm{H}_{2} \mathrm{O}$ ) & 30.3 & Ant & 7.1 \\
\hline 4-Acetamidoantipyrine & 22.0 & Fluo & 14.2 \\
\hline Phenazone & 13.2 & Pyrene & 10.6 \\
\hline Fluconazole & 2.3 & $\mathrm{BaA}$ & 4.7 \\
\hline Diazepam & 3.1 & Chry & 7.7 \\
\hline Metronidazole & 37.5 & $\mathrm{BbF}$ & 3.8 \\
\hline \multirow[t]{5}{*}{ Carbamazepine } & 0.7 & $\mathrm{BkF}$ & 2.2 \\
\hline & & $\mathrm{BaP}$ & 4.2 \\
\hline & & Ind & 4.9 \\
\hline & & DBA & 1.9 \\
\hline & & BghiP & 5.5 \\
\hline Total & 151.7 & & 368.9 \\
\hline Household chemicals & $\begin{array}{l}\text { annual load } \\
\text { (t/yr) }\end{array}$ & Pesticides & $\begin{array}{l}\text { annual load } \\
(\mathrm{t} / \mathrm{yr})\end{array}$ \\
\hline Caffeine & 48.7 & Carbendazim & 36.2 \\
\hline Sucralose & 169 & Atrazine & 10.0 \\
\hline Benzotriazole & 32.5 & Prometryn & 4.6 \\
\hline 4-/5-Methyl-Benzotriazole & 12.4 & Metolachlor & 7.0 \\
\hline DEET & 7.7 & Atrazine-hydroxy & 25.4 \\
\hline \multirow[t]{3}{*}{ Climbazole } & 1.8 & Atrazine-desethyl & 2.6 \\
\hline & & Atrazine-desisopropyl & 4.8 \\
\hline & & Imidacloprid & 6.9 \\
\hline Total & 272.7 & & 97.5 \\
\hline
\end{tabular}




\section{Appendix 2. Supplementary data}

Supplementary data to this article can be found online at http://dx. doi.org/10.1016/j.scitotenv.2013.11.019.

\section{References}

Bao Z, Zhang Z. Identification and analysis of organics in Yangtze River. Environ Chem (in Chinese) 1990;9(4):1-8.

Bouloubassi I, Fillaux J, Saliot A. Hydrocarbons in surface sediments from the Changjiang (Yangtze River) Estuary, East China Sea. Mar Pollut Bull 2001;42/12:1335-46.

Buerge JI, Poiger T, Müller DM, Buser HR. Caffeine, an anthropogenic marker for wastewater contamination of surface waters. Environ Sci Technol 2003;37:691-700.

Cauwet G, Mackenzie FT. Carbon inputs and distribution in estuaries of turbid rivers: The Yang Tze and Yellow Rivers (China). Mar Chem 1993:43:235-46.

Chen SJ, Gao XJ, Mai BX, Chen ZM, Luo XJ, Sheng GY, et al. Polybrominated diphenyl ethers in surface sediments of the Yangtze River Delta: Levels, distribution and potential hydrodynamic influence. Environ Pollut 2006;144:951-7.

Clark MG, Goolsby AD, Battaglin AW. Seasonal and annual load of herbicides from the Mississippi River Basin to the Gulf of Mexico. Environ Sci Technol 1999;33/7:981-6.

Duan SW, Liang T, Zhang S, Wang LJ, Zhang XM, Chen XB. Seasonal changes in nitrogen and phosphorus transport in the lower Changjiang River before the construction of the Three Gorges Dam. Estuar Coast Shelf Sci 2008;79:239-50.

Dudgeon D. Requiem for a river: extinctions, climate change and the last of the Yangtze. Aquat Conserv 2010;20:127-31.

Feng CL, Xia XH, Shen ZY, Zhou Z. Distribution and sources of polycyclic aromatic hydrocarbons in Wuhan section of the Yangtze River, China. Environ Monit Assess 2007a;133:447-58.

Feng JL, Yang ZF, Niu JF. Remobilization of polycyclic aromatic hydrocarbons during the resuspension of Yangtze River sediments using a particle entrainment simulator. Environ Pollut 2007b;149:193-200.

Gfrerrer M, Dieter Martens, Gawlik B, Wenzi T, Zhang AQ, Quan X, et al. Triazines in the aquatic systems of the Eastern Chinese Rivers Liao-He and Yangtse. Chemosphere 2002;47:455-66

Giger W, Schaffner C, Kohler HP. Benzotriazole and tolyltriazole as aquatic contaminants. 1. Input and Occurrence in Rivers and Lakes. Environ Sci Technol 2006;40:7186-92.

Gioia R, Dachs J. The riverine input-output paradox for organic pollutants. Front Ecol Environ 2012;10/8:405-6.

Harvey RG. Polycyclic aromatic hydrocarbons: Chemistry and Carcinogenicity. New York: Cambridge University Press; 1991

He H, Hu GJ, Sun C, Chen SL, Yang MN, Li J, et al. Trace analysis of persistent toxic substances in the main stream of Jiangsu section of the Yangtze River, China. Environ Sci Pollut Res Int 2011;18:638-48.

Heeb F, Singer H, Pernet-Coudrier B, Qi WX, Liu HJ, Longree P, et al. Organic micropollutants in rivers downstream of the megacity Beijing: sources and mass fluxes in a large-scale wastewater irrigation system. Environ Sci Technol 2012;46: 8680-8.

Hui YM, Zheng MH, Liu ZT, Gao LR. Distribution of polycyclic aromatic hydrocarbons in sediments from Yellow River Estuary and Yangtze River Estuary, China. J Environ Sci 2009;21:1625-31.

Jiang X, Martens D, Schramm KW, Kettrup A, Xu SF, Wang LS. Polychlorinated organic compounds (PCOCs) in waters, suspended solids and sediments of the Yangtse River. Chemosphere 2000;41/6:901-5

Kahle M, Buerge JI, Müller DM, Poiger T. Hydrophilic anthropogenic markers for quantification of wastewater contamination in ground- and surface waters. Environ Toxicol Chem 2009;28/12:2528-36

Lerch NR, Donald WW, Li YX, Alberts EE. Hydroxylated atrazine degradation products in a small Missouri stream. Environ Sci Technol 1995;29:2759-68.

Lerch NR, Blanchard EP, Thurman ME. Contribution of hydroxylated atrazine degradation products to the total atrazine load in midwestern streams. Environ Sci Technol 1998;32:40-8.

Li DJ, Dag D. Ocean pollution from land-based sources: East China Sea, China. AMBIO 2004;33/1:107-13.

Liu M, Baugh PJ, Hutchinson SM, Yu L, Xu S. Historical record and sources of polycyclic aromatic hydrocarbons in core sediments from the Yangtze Estuary, China. Environ Pollut 2000;110:357-65.

Liu B, McConnell LL, Torrents A. Herbicide and insecticide loadings from the Susquehanna River to the Northern Chesapeake Bay. J Agric Food Chem 2002;50:4385-92.

Liu M, Yang Y, Hou L, Xu S, Ou D, Zhang B, et al. Chlorinated organic contaminants in surface sediments from the Yangtze Estuary and nearby coastal areas, China. Mar Pollut Bull 2003;46:659-76.

Liu M, Cheng SB, Ou DN, Yang Y, Liu HL, Hou LJ, et al. Organochlorine pesticides in surface sediments and suspended particulate matters from the Yangtze estuary, China. Environ Pollut 2008;156:168-73.

Mai BX, Fu JM, Sheng GY, Kang YH, Lin Z, Zhang G, et al. Chlorinated and polycyclic aromatic hydrocarbons in riverine and estuarine sediments from Pearl River Delta, China. Environ Pollut 2002;117:457-74.

Mead RN, Morgan JB, Avery JB, Kieber JR, Kirk MA, Skrabal AS, et al. Occurrence of the artificial sweetener sucralose in coastal and marine waters of the United States. Mar Chem 2009;116:13-7.

Müller B, Berg M, Yao ZP, Zhang XF, Wang D, Pfluger A. How polluted is the Yangtze river? Water quality downstream from the Three Gorges Dam. Sci Total Environ 2008;402: 232-47.
Müller B, Berg M, Pernet-Coudrier B, Qi WX, Liu HJ. The geochemistry of the Yangtze River: Seasonality of concentrations and temporal trends of chemical loads. Glob Biogeochem Cycles 2012;26/2. http://dx.doi.org/10.1029/2011GB004273.

NBSC, National Bureau of Statistics of China. China Statistical Yearbook. China Statistics Press; 2010.

Nielsen T. Traffic contribution of polycyclic aromatic hydrocarbons in the center of a large city. Atmos Environ 1996;30/20:3481-90.

Oppenheimer J, Eaton A, Badruzzaman M, Haghani WA, Jacangelo GJ. Occurrence and suitability of sucralose as an indicator compound of wastewater loading to surface waters in urbanized regions. Water Res 2011;45:4019-27.

Panshin SY, Carter DS, Bayless ER. Analysis of atrazine and four degradation products in the pore water of the vadose zone, central India. Environ Sci Technol 2000:34(11):2131-7.

Qiao M, Wang CX, Huang SB, Wang DH, Wang ZJ. Composition, sources, and potentia toxicological significance of PAHs in the surface sediments of the Meiliang Bay, Taihu Lake, China. Environ Int 2006;32:28-33.

Qiu J. Trouble on the Yangtze. Science 2012;336/20:288-91.

Radke M, Ulrich H, Wurm C, Kunkel U. Dynamics and attenuation of acidic pharmaceuticals along a river stretch. Environ Sci Technol 2010;44:2968-74.

Reemtsma T, Miehe U, Duennbier U, Jekel M. Polar pollutants in municipal wastewate and the water cycle: Occurrence and removal of benzotriazoles. Water Res 2010;44: 596-604.

Shen M, Yu YJ, Zheng JG, Yu HX, Lam P, Feng JF, et al. Polychlorinated biphenyls and polybrominated diphenyl ethers in surface sediments from the Yangtze River Delta. Mar Pollut Bull 2006;52:1299-309.

Singer H, Jaus S, Hanke I, Lück A, Hollender J, Alder CA. Determination of biocides and pesticides by on-line solid phase extraction coupled with mass spectrometry and their behavior in wastewater and surface water. Environ Pollut 2010;158:3054-64.

Standley JL, Kaplan AL, Smith D. Molecular tracers of organic matter sources to surface water resources. Environ Sci Technol 2000;34:3124-30.

Steen R, Hattum VB, Brinkman U. A study on the behaviour of pesticides and their transformation products in the Scheldt estuary using liquid chromatography electrospray tandem mass spectrometry. J Environ Monit 2000;2:597-602.

Sui Q, Huang J, Deng SB, Yu G, Fan Q. Occurrence and removal of pharmaceuticals, caffeine and DEET in wastewater treatment plants of Beijing, China. Water Res 2010;44:417-26.

Sun C, Dong Y, Xu S, Yao S, Dai J, Han S, et al. Trace analysis of dissolved polychlorinated organic compounds in the water of the Yangtse River (Nanjing, China). Environ Pollut 2002;117/1:9-14

Sun HG, Han J, Lu XX, Zhang SR, Li D. An assessment of the riverine carbon flux of the Xijiang River during the past 50 years. Quat Int 2010;226:38-43.

Tamtam F, Mercier F, Bot LB, Eurin J, Dinh TQ Clément M, et al. Occurrence and fate of antibiotics in the Seine River in various hydrological conditions. Sci Total Environ 2008;393:510-6.

Tang ZW, Yang ZF, Shen ZY, Niu JF. Pentachlorophenol residues in suspended particulate matter and sediments from the Yangtze River catchment of Wuhan, China. Bull Environ Contam Toxicol 2007;78:158-62.

Tollefsen EK, Nizzetto L, Huggett BD. Presence, fate and effects of the intense sweetene sucralose in the aquatic environment. Sci Total Environ 2012;438:510-6.

Torres C, Ramakrishna S, Chiu CA, Nelson GK, Westerhoff P, Krajmalnik-Brown R. Fate of sucralose during wastewater treatment. Environ Eng Sci 2011;28/5:325-32.

Voutsa D, Hartmann P, Schaffner C, Benzotriazoles Giger W. alkylphenols and bisphenol A in municipal wastewaters and in the Glatt River, Switzerland. Environ Sci Pollut Res 2006;13/5:333-41.

Wang MY, Zhao GJ, Zhang S. The transport of carbon, nitrogen, phosphorus and sulfur in the Changiiang. In: Zhang S, editor. The Background Study of Chemical Elements in the Water Environments. Beijing: Mapping Publisher; 1989. p. 122-31 [in Chinese]

Wang F, Xia XH, Sha YJ. Distribution of phthalic acid esters in Wuhan section of the Yangtze River, China. J Hazard Mater 2008;154:317-24.

Wang XC, Ma HQ Li RH, Song ZS, Wu JP. Seasonal fluxes and source variation of organic carbon transported by two major Chinese Rivers: The Yellow River and Changjiang (Yangtze) River. Glob Biogeochem Cycles 2012;26. http://dx.doi.org/10.1029/ 2011GB004130.

Wolf A, Bergmann A, Wilken RD, Gao X, Bi Y, Chen H, et al. Occurrence and distribution of organic trace substances in waters from the Three Gorges Reservoir, China. Environ Sci Pollut Res 2013. http://dx.doi.org/10.1007/s11356-013-1929-x.

Wu Y, Zhang J, Liu SM, Zhang ZF, Yao QZ, Hong GH, et al. Sources and distribution of carbon within the Yangtze River system. Estuar Coast Shelf Sci 2007;71:13-25.

Wu B, Zhao DY, Zhang Y, Zhang XX, Cheng SP. Multivariate statistical study of organic pollutants in Nanjing reach of Yangtze River. J Hazard Mater 2009; 169:1093-8.

Xia B, Zhang LJ. Carbon distribution and fluxes of 16 rivers discharging into the Bohai Sea in summer. Acta Oceanol Sin 2011;30/3:43-54.

Xu S, Jiang X, Wang X, Tan Y, Sun C, Feng J, et al. Persistent pollutants in sediments of the Yangtse River. Bull Environ Contam Toxicol 2000;64:176-83.

Xu SY, Gao XJ, Liu M, Chen ZL. China's Yangtze estuary II. Phosphorus and polycyclic aromatic hydrocarbons in tidal flat sediments. Geomorphology 2001:41:207-17.

Xu SS, Liu WX, Tao S. Emission of polycyclic aromatic hydrocarbons in China. Environ Sci Technol 2006;40:702-8.

Yan CX, Yang Y, Zhou JL, Liu M, Nie MH, Shi H, et al. Antibiotics in the surface water of the Yangtze Estuary: Occurrence, distribution and risk assessment. Environ Pollut 2013;175:22-9.

Yang ZF, Shen ZY, Gao F, Tang ZW, Niu JF. Occurrence and possible sources of polychlorinated biphenyls in surface sediments from the Wuhan reach of the Yangtze River, China. Chemosphere 2009;74:1522-30.

Yang Y, Fu J, Peng H, Hou L, Liu M, Zhou JL. Occurrence and phase distribution of selected pharmaceuticals in the Yangtze Estuary and its coastal zone. J Hazard Mater 2011a;190:588-96. 
Yang ZF, Tang ZW, Shen ZY, Niu JF, Wang HY. One-hundred-year sedimentary record of polycyclic aromatic hydrocarbons in urban lake sediments from Wuhan, central China. Water Air Soil Pollut 2011b;217:577-87.

Yang H, Xie P, Ni LY, Flower JR. Pollution in the Yangtze. Science 2012;337/27: 410.

Yang X, Chen F, Meng FG, Xie YY, Chen H, Young K, et al. Occurrence and fate of PPCPs and correlations with water quality parameters in urban riverine waters of the Pearl River Delta, South China. Environ Sci Pollut Res 2013;20:5864-75.
Zhang QF, Lou ZP. The environmental changes and mitigation actions in the Three Gorges Reservoir region, China. Environ Sci Policy 2011;14:1132-8.

Zhang Q Xu CY, Becker S, Jiang T. Sediment and runoff changes in the Yangtze River basin during past 50 years. J Hydrol 2006;331:511-23.

Zhang SY, Zhang Q Darisaw S, Ehie O, Wang GD. Simultaneous quantification of polycyclic aromatic hydrocarbons (PAHs), polychlorinated biphenyls (PCBs), and pharmaceuticals and personal care products (PPCPs) in Mississippi river water, in New Orleans, Louisiana, USA. Chemosphere 2007;66/6:1057-69. 